SJ Quinney College of Law, University of Utah Utah Law Digital Commons

2019

Conflicts of Interest and Academic Research

Jorge L. Contreras

Mark Rinehart

Follow this and additional works at: https://dc.law.utah.edu/scholarship

Part of the Business Organizations Law Commons, and the Health Law and Policy Commons 
Research Handbook on Intellectual Property and Technology Transfer (Jacob Rooksby, ed., Edward Elgar, 2019, forthcoming)

\title{
CONFLICTS OF INTEREST AND ACADEMIC RESEARCH
}

\author{
Jorge L. Contreras ${ }^{1}$ and Marc Daniel Rinehart ${ }^{2}$
}

\section{INTRODUCTION}

In September 2018, the front page of the New York Times bore the headline "Top Cancer Researcher Fails to Disclose Corporate Financial Ties in Major Research Journals." ${ }^{3}$ The story revealed that world-renowned oncologist José Baselga, Chief Medical Officer of Memorial Sloan Kettering Cancer Center in New York, received more than $\$ 3$ million from pharmaceutical and biotechnology firms between 2013 and 2017, and failed to disclose these payments in dozens of articles and speeches commenting, in many cases, on drugs being developed by those very companies. Dr. Baselga resigned a few days after these revelations were published.

The influence that corporate funders may exert over academic research has generated significant controversy both within and outside the academy. Corporate funding of academic research began quietly in the 1950s when the tobacco industry sought to generate academic debate over findings that linked smoking with cancer. ${ }^{4}$ The results of this campaign were not generally known, however, until much later. In 1974, public concern over corporate support for academic research began to emerge when Monsanto was reported to have paid Harvard Medical School \$23 million to conduct research on organ development. ${ }^{5}$ Other multi-million dollar transactions followed as corporations increasingly sought to benefit from research conducted at leading academic institutions. ${ }^{6}$ Alongside these transactions between industry and academic institutions, news began to

${ }^{1}$ Professor, University of Utah S.J. Quinney College of Law and Adjunct Professor, Department of Human Genetics, University of Utah School of Medicine. Contreras acknowledges support from the Huntsman Cancer Institute/Huntsman Cancer Foundation and the Utah Center for Genomic Innovation. Contreras is a member of the University of Utah Conflicts of Interest Committee.

${ }^{2}$ Director, Conflict of Interest Office, University of Utah. Rinehart acknowledges the assistance of Professor Amelia Rinehart in preparing this chapter.

${ }^{3}$ Charles Ornstein \& Katie Thomas, Top Cancer Researcher Fails to Disclose Corporate Financial Ties in Major Research Journals, N.Y. TIMES, Sep. 8, 2018 (p. A1).

${ }^{4}$ See Allan M. Brandt, Inventing Conflicts of Interest: A History of Tobacco Industry Tactics, 102 AM. J. Pub. Health, 63, 67 (2012) ("the tobacco industry managed to sustain the widespread perception of an active and highly contested scientific controversy into the 1960s despite overwhelming evidence and scientific consensus that smoking caused serious disease").

${ }^{5}$ Edward B. Fiske, Monsanto Research Pact Aims to Cut Academic Controversy, N.Y. Times, Jun. 4, 1982, at A21.

${ }^{6}$ See Fiske, supra note 5, JenNifer WASHBURn, UniVersity Inc. - THE CORPORATE CORRUPTION OF HigHER EDUCATION 4-5 (2005). 
spread that individual researchers could profit - sometimes substantially - from their academic research. ${ }^{7}$

Growing ties between industry and academia generated significant public opposition in the late 1990 s and early 2000 s, when student protests at institutions including University of California Berkeley, ${ }^{8}$ University of California at Davis, ${ }^{9}$ and Yale Medical School ${ }^{10}$ led to the revision of significant corporate funding arrangements. Consumer advocate Ralph Nader expressed the fears of many in 2004 when he wrote:

Academic science, with its custom of open exchange, its gift relationships, its willingness to provide expert testimony that speaks truth to power, its serendipitous curiosity and its nonproprietary legacy to the next generation of student-scientists, differs significantly from corporate science, which is ridden with trade secrets, profit-determined selection of research, and awesome political power to get its way, whether by domination or servility to its payers. ${ }^{11}$

A few years later, journalist Dan Greenberg, in his influential book Science for Sale: The Perils, Rewards, and Delusions of Campus Capitalism, posed the following question after interviewing researchers, university administrators and academic technology transfer officials across the country:

Have today's commercial values contaminated academic research, diverting it from socially beneficial goals to mercenary service on behalf of profit-seeking corporate interests? What are the gains and losses in the visibly tightening linkage of science and mammon, and to whose benefit and whose detriment? Can academic institutions, with their insatiable appetite for money, reap financial profits from their production of valuable knowledge without damage to the soul of science and the public? ${ }^{12}$

In 2008, a string of highly-publicized failures of academic investigators to disclose significant industry compensation led to a Congressional investigation of academic conflicts of interest. ${ }^{13}$ A 2012 report by the non-partisan Congressional Research Service also recognized the threat of conflicts of interest arising from increased patenting and

\footnotetext{
${ }^{7}$ See Sheldon Krimsky, Science In the Private InTEREST - HAS THE LuRE OF Profits CORRUPTED BIOMEDICAL RESEARCH? 110 (pbk. ed. 2004) (finding that between 1985-88, 31\% of biology faculty at MIT had ties to a biotechnology company, with $20 \%$ at Harvard and Stanford); Eliot Marshall, When Commerce and Academe Collide, 248 SCIENCE 152 (1990).

8 See Washburn, supra note 6, at 7-8 (describing controversy over corporate sponsorship by Novartis).

${ }^{9}$ See id. at 95 (controversy over support of agricultural research by Allied Chemical).

10 See Donald G. McNeil, Jr., Yale Pressed to Help Cut Drug Costs in Africa, N.Y. Times, Mar. 12, 2001, at A3 (describing student protests over agreement with Bristol-Myers Squibb regarding AIDS drug d4T).

${ }^{11}$ Ralph Nader, Foreword in KRIMSKY, supra note 7, xiii, xiv.

12 Daniel S. Greenberg, Science for Sale: The Perils, Rewards, and Delusions of Campus CAPITALISM 2 (2007).

13 See Gardiner Harris, Top Psychiatrist Didn't Report Drug Makers' Pay, N.Y. TIMES, Oct. 3, 2008.
} 
technology commercialization by universities and the debate regarding the severity of this threat. $^{14}$

In response to these concerns, the academic research enterprise - researchers, research institutions, funders of academic research and scientific journals - have given renewed attention to potential conflicts of interest between researchers, institutions and external funding sources. Many of these groups have adopted formal policies and procedures concerning conflicts of interest. In this chapter, we summarize some of the procedures implemented by these different stakeholders in the research enterprise to reduce the impact of conflicts of interest. ${ }^{15}$

\section{WHAT ARE CONFLICTS OF INTEREST?}

Many definitions of "conflict of interest" ("COI") exist. ${ }^{16}$ As defined in an influential 2009 report by the Institute of Medicine, a conflict constitutes any "set of circumstances that creates a risk that professional judgment or actions regarding a primary interest will be unduly influenced by a secondary interest." ${ }^{17}$ Thus, a familial or romantic relationship, a personal animus, a professional friendship or rivalry, a religious belief, and even an unconscious bias, could all affect research outcomes and be considered conflicts of interest. ${ }^{18}$ However, for a host of practical reasons, formal conflict of interest policies typically focus on financial relationships and the potential for financial gain. ${ }^{19}$ Thus, financial conflicts of interest will be the focus of this chapter. ${ }^{20}$

${ }_{14}$ Wendy H. Schacht, The Bayh-Dole Act: Selected Issues in Patent Policy and Commercialization of Technology, Congressional Research Service 17-19 (Dec. 3, 2012).

15 Though our focus in this chapter is on COI policies and regulations in the United States, issues surrounding COI are by no means limited to the United States. See, e.g., MARK A. RodwIn, ConfLICTS OF INTEREST AND the Future OF Medicine: THE United StATES, FranCE AND JAPAN 6 (2011) ("Conflicts of interest are endemic in private practice in countries with very different medical, legal and political systems").

16 See Mark A. Rodwin, Conflicts Of Interest In Medicine: Should We Contract, Conserve, or Expand the Traditional Definition and Scope Of Regulation? 22 J. HEAlth CARE L. \& POLICY 158 (forthcoming 2019) (discussing and critiquing definitional inconsistencies).

${ }^{17}$ Inst. of Med. (IOM), Conflict of Interest in Medical Research, Education and Practice 45-46 (Bernard Lo \& Marilyn J. Field, eds. 2009) [hereinafter IOM 2009].

18 See, e.g., IOM 2009, supra note 17, at 46-47, Inst. of Med. (IOM), Conflict of Interest and Medical Innovation: Ensuring Integrity While Facilitating Innovation in Medical Research - Workshop Summary 8 (Sarah H. Beachy, Adam C. Berger \& Steve Olson, Rapporteurs, 2014) [hereinafter IOM 2014], Lisa Bero, Addressing Bias and Conflict of Interest Among Biomedical Researchers, 317 J. Am. Med. Assn. 1723,1723 (2017).

${ }^{19}$ See IOM 2009, supra note 17, at 47; Bero, supra note 18, at 1723 (meta-analyses have shown that financial conflicts of interest have a measurable effect on research outcomes).

${ }^{20}$ But see Ross E. McKinney \& Heather H. Pierce, Strategies for Addressing a Broader Definition of Conflicts of Interest, 317 J. AM. MED. ASSN. 1727 (2017) (arguing for policies to address non-financial conflicts of interest). 
This being said, there is little consensus regarding the size of a financial interest that gives rise to a conflict of interest. As discussed below, different federal requirement at different times have required disclosure of financial interests in excess of $\$ 10,000$, $\$ 5,000$ and $\$ 200$. While some academic investigators and clinicians receive tens of millions of dollars in outside compensation, ${ }^{21}$ others receive mere token amounts, free meals or travel reimbursement. Nevertheless, studies have shown that even relatively small levels of compensation can have an impact on research results and reporting. ${ }^{22}$

As suggested in the Introduction to this chapter, financial conflicts of interest can occur both at the individual level and at the institutional level. The policies described below are directed primarily to individual conflicts of interest. Identifying and addressing institutional conflicts of interest has proven far more difficult, ${ }^{23}$ though some policies have taken steps in this direction.

Before addressing specific policies, it is worth considering how financial conflicts of interest can affect research. As an investigator plans a study, including the formulation of a hypothesis, the selection of methodologies and the design of study protocols, a significant interest could influence the investigator's choices. Because the role and responsibilities of the investigator vary with the type of research being conducted, the potential for bias in experimental design created by the significant financial conflict of interest varies as well. For example, an industry sponsor often designs experimental protocols with little to no input from investigators conducting the research at a home institution to standardize inter-institutional research and to meet criteria assigned by the Food and Drug Administration ("FDA"). In such cases, even an investigator with a significant financial interest related to the industry sponsor cannot impart bias on the design of the study. ${ }^{24}$ In such cases, even direct remuneration for consulting services does not appear to represent a direct and significant relationship with the investigator's role and responsibility in the design of the study - and a financial conflict of interest would not exist.

But if an investigator independently designed a study that compared the efficacy of two FDA-approved drugs and the investigator received direct remuneration from one of the manufacturers of the drugs, a potential for bias in the experimental design of the study would exist. The investigator would have a financial conflict of interest due to her outside

${ }^{21}$ See Bernard Lo \& Deborah Grady, Payments to Physicians: Does the Amount of Money Make a Difference? 317 J. AM. MED. ASSN. 1719 (2017) ("The 5 physicians who received the largest total payments in the Open Payments database from 2013 through 2015 each received more than \$28 million”).

22 See id. at 1720 (even meals costing between $\$ 12$ and $\$ 18$ have been shown to affect physician prescribing practices); Harvey V. Fineberg, Conflict of Interest -Why Does it Matter? 317 J. AM. MED. ASSN. 1717 (2017) (even small gifts such as return address labels in charitable solicitations and stamped return envelopes can significantly increase physician return rates).

23 See Greenberg, supra note 12, at 160 ("institutional conflicts of interest presented a tangle of problems that had heretofore been ignored").

${ }^{24}$ This is assuming that the researcher's financial interest in the company was not related to assisting in designing the study for FDA approval. Does FDA criteria allow for some flexibility in experimental design that could be unduly influenced by bias created by a financial interest in the company? 
relationship with the manufacturer due to her role and responsibility in experimental design.

Likewise, an investigator who does not form the hypothesis, design the experiments, or assign the methodology used in a research project, but who takes an active role in the conduct of the research may still be influenced by a significant financial interest. Such influence could manifest itself through myriad activities by the investigator during the research study. For example, an investigator working in a research study involving patients may decide exclusion and inclusion criteria for enrolling patients in the study or may be involved in consent decisions. If the research study has an industry sponsor, the investigator also may recruit patients, conduct medical evaluations of the patients during the trial, and in some circumstances, analyze the resultant data. Each of these activities might be affected adversely if there is a conflict of interest.

Financial conflicts of interest might also affect the conduct of a study through data analysis. An investigator might "cherry-pick" data by excluding data points identified as outliers or choose a statistical test for analysis that yields desired results. ${ }^{25}$ Finally, a biased investigator might draw overstated or unfounded conclusions, fail to disclose funding sources or financial interests relevant to readership and the community at large, fail to report results not supported by the significant financial interests, or fail to report null results. In each of these instances, the research in question would be undermined by these decisions.

A final, yet critical, area in which conflicts of interest can affect research arises with respect to the treatment of human subjects. Human subjects research is heavily regulated in the United States under a variety of administrative schema including the so-called Common Rule which imposes requirements on the conduct of federally-funded human subjects research. ${ }^{26}$ There has long been concern that researchers with financial conflicts of interest may make decisions regarding human subjects that are compromised, thus imposing risks to individual health and welfare. ${ }^{27}$ Accordingly, policies relating to conflicts of interest are also intended to protect human subjects in research.

\footnotetext{
${ }^{25}$ It may seem intuitive that statistical analysis of data sets should be rigorous and be selected based on the design of the experiment. However, the field of statistics is becoming ever more complex as new technologies lead to more complex experimental designs with more variables to analyze. This has resulted in ambiguity in assigning proper statistical analyses to more complex experiments. Silberzahn et al. have shown that even experts in the field of statistics are vulnerable to bias and uncertainty when deciding best practices. In their experiment they gave several groups of statisticians the same data set to analyze using their own discretion in selecting the proper statistical evaluations. The distribution of the groups' results was striking with some groups finding statistical significance to support the hypothesis while other groups found the results did not significantly support the hypothesis. In a twist, the researchers then had the groups share their methods and opened discussion so that all the groups considered the others approach. The groups, now armed with new approaches and considerations, re-evaluated the data with what should have been more similar statistical tests. The results of the second analysis showed a similar distribution and variability as the first analysis. The results of this study suggest that even without undue bias in the form of external financial interests devising proper studies with appropriate analyses can prove difficult. R. Silberzahn et al., Many Analysts, One Data Set: Making Transparent How Variations in Analytic Choices Affect Results. 1 Advances in Methods \& Practices In Psychol. Sci. 337 (2018).

${ }^{26}$ Federal Policy for the Protection of Human Subjects, 45 C.F.R. Part 46.

${ }^{27}$ See, e.g., Dept. Health \& Human Services, Financial Conflict of Interest - HHS Guidance 2004,
} 
As described above, many conflicts of interests can bias research outcomes or impose risks on human subjects. However, even conflicts that do not have any tangible effect on research can give an appearance of bias. In many cases, this appearance of bias can be just as damaging to an investigator's or an institution's reputation as actual bias. Thus, as McCoy and Emanuel explain, there are no "potential" conflicts of interest. ${ }^{28}$ Rather, "a COI describes a situation in which there is a risk of bias and resulting harm, not a situation in which bias or harm necessarily occurs. Thus, a situation marked by risk of bias from a secondary interest is no less a COI because it does not result in bias or harm." For these reasons, the policies discussed below address conflicts of interest whether or not bias or harm resulted.

\section{GOVERnMENTAL CONFLICT OF INTEREST POLICIES}

\section{a. Individual conflicts of interest}

The first formal U.S. agency rules addressing conflicts of interest were adopted by the National Science Foundation ("NSF") ${ }^{29}$ and the Department of Health and Human Services ("HHS") through its Public Health Service ("PHS") 30 almost concurrently in 1995. These rules applied to each institution receiving research funding from the agency (grantees). These early rules established an approach to dealing with conflicts of interest based primarily on disclosure, an approach that has persisted through the present day.

In the case of PHS (including the Naitonal Intsitutes of Health ("NIH")), a grantee institution had to require each investigator planning to participate in PHS-funded research to disclose to a designed institutional official any "significant financial interest" that "would reasonably appear to be affected by the research" or "in entities whose financial interests would reasonably appear to be affected by the research." 31 For this purpose, a "significant financial interest" was anything of monetary value (including salary, consulting fees and honoraria), equity interests and intellectual property ("IP") rights held by the investigator or members of his or her immediate family valued, in the aggregate, at more than $\$ 10,000$ or representing more than $5 \%$ of the value of a single entity." 32 The grantee was required to notify PHS of the existence of any such conflict (but not the nature of the interest or other details) and to assure PHS that the interest was "managed, reduced

https:/www.hhs.gov/ohrp/regulations-and-policy/guidance/financial-conflict-of-interest/index.html.

${ }^{28}$ Matthew S. McCoy \& Ezekiel J. Emanuel, Why There Are No 'Potential' Conflicts of Interest, 317 J. Am. MeD. Assn. 1721, 1721 (2017).

${ }^{29}$ Natl. Science Foundation, Investigator Financial Disclosure Policy, 60 Fed. Reg. 35820 (1995).

${ }^{30}$ Dept. Health \& Human Services, Objectivity in Research, 60 Fed. Reg. 35810 (1995), codified at 42 CFR Part 50, Subpart F (1995).

3145 CFR Part 50, Subpart F, § 50.604(a)-(c) (1995).

${ }^{32} I d$. at $\S 50.603$. 
or eliminated." ${ }^{33}$ In addition, the grantee was required to disclose specific information regarding the interest to PHS upon request. ${ }^{34}$

These rules, which left the review and administration of conflicts of interest almost entirely to grantee institutions, was viewed by critics as "well-intentioned but soft." 35 Moreover, the pace of industry support of academic research continued to increase. One study found that, from 1994 to 2003, financial support of biomedical research in the U.S. increased from $\$ 37.1$ billion to $\$ 94.3 .{ }^{36}$ Likewise, relationships between individual academic researchers and industry increased from $28 \%$ in 1996 to $52.8 \%$ in $2007 .{ }^{37}$ In addition, news stories continued to break regarding egregious instances of academic misfeasance and failure to disclose major corporate research funding. ${ }^{38}$ As a result, PHS revised its COI policy in 2011 after a 60-day public review and comment period. ${ }^{39}$

The 2011 rules made a number of changes to PHS's 1995 COI rules. First, the threshold for a "significant financial interest" was lowered from $\$ 10,000$ to $\$ 5,000.40$ Second, the term "financial conflict of interest" was defined as "a significant financial interest that could directly and significantly affect the design, conduct, or reporting of PHSfunded research." ${ }^{41}$ Third and most importantly, the 2011 rules require that grantee institutions take measures to manage disclosed conflicts of interest through a variety of means including: public disclosure of the COI, disclosure of the COI to individual human subjects, appointment of an independent monitor capable of protecting the research against bias, modification of the research plan or research team, reduction or elimination of the COI, or disqualification of conflicted personnel from the research project. ${ }^{42}$ The granting institution is also required to disclose the COI to PHS and certify that it has implemented a suitable management plan. ${ }^{43}$ The specific impact of the 2011 policy on some institutional COI policies is discussed in greater detail in Section III, below.

${ }^{33} \mathrm{Id}$. at $\S 50.604(\mathrm{~g})(2)$.

${ }^{34} \mathrm{Id}$. at $\S 50.604(\mathrm{~g})(3)$.

${ }^{35}$ Greenberg, supra note 12, at 160.

${ }^{36}$ Hamilton Moses, Ray Dorsey, David H.M. Matheson, Financial Anatomy of Biomedical Research, 294 J. AM. MED. ASSN.1333 (2005).

${ }^{37}$ D. Blumenthal et al., 335 N EngL. J. Med. 1734 (1996); D.E. Zinner et al., 28 HeAlth AfFAIRs 1814 (2009).

${ }^{38}$ See, e.g., Sara Reardon, NIH Disclosure Rules Falter, 525 NAtURe 300, 300 (2015) (A 2008 U.S. Senate investigation revealed that an Emory University psychiatric researcher failed to disclose at least $\$ 1.2$ million that he had received from drug companies).

${ }^{39}$ Dept. Health \& Human Services, Responsibility of Applicants for Promoting Objectivity in Research for which Public Health Service Funding is Sought and Responsible Prospective Contractors, 76 Fed. Reg. 53256 (2011), codified at 42 CFR Part 50 (2011).

4045 CFR Part 50, Subpart F, § 50.603 (2011).

${ }^{41} I d$.

${ }^{42} I d$. at $\S 50.605(\mathrm{a})(1)$.

${ }^{43} I d$. at $\S 50.605(\mathrm{~b})$. 
If an institution discovers that an investigator has failed to disclose a COI as required under the PHS rules, and that failure "appears to have biased the design, conduct, or reporting" of the relevant research, the institution is required to report the failure to the relevant PHS entity. ${ }^{44}$ The relevant PHS entity may also review the institution's relevant records to assess the potential for COI-based bias and to verify that an investigator has complied with any management plan imposed to address a COI. ${ }^{45}$ In each of these cases, the PHS entity may impose specific corrective or remedial measures on the institution and investigator. ${ }^{46}$ In severe cases, additional federal remedies are available, including debarment and suspension of the institution and/or investigator from further PHS grant funding, and liability under civil fraud regulations. ${ }^{47}$

\section{b. Institutional conflicts of interest}

Interestingly, neither the 1995 nor the 2011 PHS rules addresses institutional conflicts of interest. In the public comment solicitation preceding the adoption of the 1995 rules, PHS asked members of the public to comment on whether the new regulations should address institutional COI. ${ }^{48}$ More than 100 comments were received. ${ }^{49}$ According to PHS, "those addressing the issue were nearly unanimous in concluding that the regulations should not address the institutional conflict issue because of the need to carefully consider that issue through a separate process." ${ }^{50}$ PHS agreed and the 1995 rules contained no references to institutional COI.

In the late 1990s, several highly-publicized incidents involving federally-funded academic research programs, including the death of a teenage volunteer in a gene therapy trial at University of Pennsylvania that was tainted by significant corporate ties. ${ }^{51}$ These incidents reinvigorated federal efforts to monitor and control institutional conflicts of interest. In 2001, the Office of Human Research Protection ("OHRP”) published a Draft Interim Guidance as a first step toward updating the 1995 COI rules. ${ }^{52}$ This document was authored by OHRP's newly appointed head, Dr. Greg Koski, director of human research

${ }^{44} I d$. at $\S 50.606(\mathrm{a})$.

${ }^{45} I d$. at $\S 50.606(\mathrm{~b})$.

${ }^{46} I d$. at $\S 50.606(\mathrm{a})$.

${ }^{47} \mathrm{Id}$. at $\S 50.607$ (citing other regulations).

${ }^{48} 60$ Fed. Reg. 35810 at 35813

${ }^{49} \mathrm{Id}$. at 35810 .

${ }^{50} \mathrm{Id}$. at 35813.

${ }^{51}$ See Greenberg, supra note 12, at 103-05 (discussing Penn incident) and 149-50 (discussing shutdown of Duke University studies for procedural violations).

${ }^{52}$ Off. Human Research Protection, Draft Interim Guidance - Financial Relationships in Clinical Research: Issues for Institutions, Clinical Investigators, and IRBs to Consider When Dealing with Issues of Financial Interests and Human Subject Protection (Jan. 10, 2001), http://ccnmtl.columbia.edu/projects/rcr/rcr_conflicts/misc/Ref/OHRP_CoI.pdf 
affairs at the Partners HealthCare system and a Harvard Medical School professor. ${ }^{53}$ Koski's draft included the following controversial provisions:

1.6 While institutions clearly need to have policies and procedures for managing conflicts of interest among their employees, they should not lose sight of the need to manage their own conflicts of interest as well. Increasingly, academic institutions and corporate entities are entering into agreements that are mutually beneficial, and which may also bring the institution's interests into direct conflict with those of research participants. For example, an institution may accept a principal equity interest in a biotechnology company as part of a cooperative endeavor to develop a new medical device. Clearly, in such a situation, both the institution and the corporate partner would stand to gain financially if the device proves to be safe and effective. Accordingly, the institution should carefully consider whether a clinical trial to evaluate safety and efficacy should be performed at that site, and if it should, what special protections would be needed. The financial interest of the institution in the successful outcome of the trial could directly influence the conduct of the trial, including enrollment of subjects, adverse event reporting or evaluation of efficacy data. In such cases, the integrity of the research, as well as the integrity of the institution and its corporate partner, and the well-being of the research participants, may be best protected by having the clinical trial performed and evaluated by independent investigators at sites that do not have a financial stake in the outcome of the trial, or carried out at the institution but with special safeguards to maximally protect the scientific integrity of the study and the research participants.

1.7 When institutions consider entering into such business agreements, they should consider establishing an independent advisory and oversight committee (institutional conflicts of interest committee), if one does not already exist, to determine whether the financial arrangements pose a conflict of interest, and if so, how those conflicts should be managed.

1.8 Any financial relationships that the institution has with the commercial sponsor of a study should be documented and the specific relationships submitted to the Chair/Staff of the IRB as described above. Items to be identified include: any equity interest in the commercial sponsor; any "up front" payments to the Institution beyond those payments directly applicable to carrying out a particular protocol; any funds given to the Institution (or an entity within the Institution, e.g. an Institute); any equity ownership in the commercial sponsor that was transferred to the Institution, including the percentage ownership of any patents related to articles under study in the protocol; any royalties; any licenses granted to the commercial sponsor by the Institution; whether or not the Institution stands to gain

${ }^{53}$ Greenberg, supra note 12, at 154. 
financially if the study shows the "article" to be successful for its proposed use.

Not surprisingly, Dr. Koski's Draft Interim Guidance generated significant opposition from the academic community. ${ }^{54} \mathrm{He}$ left OHRP and returned to Harvard shortly thereafter. ${ }^{55}$

Nevertheless, increasing public scrutiny led PHS in 2009 to consider a revision to its COI rules. Over a two-year period it held two rounds of public comment on the question of managing institutional conflicts of interest. ${ }^{56}$ PHS received a "wide range of responses" 57 to this inquiry, including calls for further research and greater specification of precisely what rules might be imposed with respect to institutional COI. Given this input, PHS concluded that "requiring Institutions to have a policy on institutional conflicts of interest without providing additional guidance as to the nature and scope of that policy would lead to confusion and inconsistencies across Institutions. We also believe that substantial additional information and deliberations are needed to formulate such guidance." 58 Accordingly, no rules regarding institutional COI were adopted, and PHS committed to "continue to consider the issue of institutional conflict of interest with the biomedical research community." 59 As of this writing, no further guidance has emerged from any significant U.S. funding agency on this topic. ${ }^{60}$

\section{c. Governmental reviewers and advisory committee members}

The policies discussed above relate to conflicts of interest by investigators at grantee institutions and the institutions themselves. In addition, the federal government has a number of COI policies that cover government employees. Most importantly, 18 U.S.C. $\S 208(a)$ imposes criminal penalties on executive branch employees who participate in any matter in which he or she, or his or her immediate family, has a financial interest. ${ }^{61}$ This prohibition applies both to regular government employees as well as individuals serving on governmental advisory committees, panels and councils, who are generally regarded as

54 Greenberg, supra note 12, at 162; Greg Koski, Research, Regulations, and Responsibility: Confronting the Compliance Myth - A Reaction to Professor Gatter, 52 EMORY L. REV. 403, 413 (2003).

${ }^{55}$ Greenberg, supra note 12, at 167.

5676 Fed. Reg. 53256 at 53257, 53278.

${ }^{57}$ Id. at 53278 .

${ }^{58} I d$.

${ }^{59} I d$.

${ }^{60}$ Discussion, however, continues. See Sandro Galea \& Richard Saitz, Funding, Institutional Conflicts of Interest, and Schools of Public Health, 317 J. AM. MED. AssN. 1735, 1735 (2017) ("schools of public health should not accept money if doing so pushes them to be something that is not consistent with their mission to promote the health of the public").

6118 U.S.C. $\S 208(a)$. 
"special" government employees ("SGE"). ${ }^{62}$ These position are often held by prominent academics and community leaders with expertise in the scientific area addressed by a particular governmental agency or institute.

SGEs must file periodic certifications of financial interests pursuant to the Ethics in Government Act of 1978. ${ }^{63}$ Unlike the COI disclosures required of grantee investigators, which only pertain to significant financial interests giving rise to a conflict of interest, SGE disclosures made on form OGE- $450^{64}$ must include all financial interests (including assets and income) of the SGE and his/her immediate family in excess of $\$ 200 .{ }^{65}$ If an SGE discloses a conflict of interest pertinent to his or her role on a governmental body, then he or she must either recuse himself or herself from the matters as to which a COI exists, or a responsible official must make a determination that the need for the individual's service outweighs the potential conflict. ${ }^{66}$

In addition to SGEs, many academics serve on peer review panels and study sections that review and evaluate grant applications for federal funding. These individuals are not subject to the same conflict of interest disclosure requirements as SGEs, but must recuse themselves from consideration of any grant application in which they have a "real conflict of interest." ${ }^{\prime 67}$

Conflicts by advisory board members have recently been in the spotlight following the results of a 2018 investigation by the journal Science, which found that of 107 physicians who advised the FDA on drug approvals, 40 received more than $\$ 10,000$ in undisclosed compensation from the manufacturers of the drugs that they voted to approve (or their competitors), and seven of these received more than $\$ 1$ million each. ${ }^{68}$ Interestingly, most of these payments were made after the vote to approve the drug, sometimes over several years. As one ethicist commented, such payments represented a way of "postponing" the "reward" for approving a company's drug. ${ }^{69}$

${ }^{62}$ See 18 U.S.C. § 202(a) (defining “special Government employee”).

${ }^{63}$ Ethics in Government Act of 1978, codified at 5 U.S.C. $\S 101$ et seq.

${ }^{64}$ Off. Govt. Ethics, Form 450: Confidential Financial Disclosure Report.

655 U.S.C. $\S 102(\mathrm{a})(1)(\mathrm{A})$.

${ }^{66} 18$ U.S.C. $\$ 208(\mathrm{~b})(3)$.

${ }^{67} 45$ CFR 52h.5. A "real conflict of interest means a reviewer or a close relative or professional associate of the reviewer has a financial or other interest in an application or proposal that is known to the reviewer and is likely to bias the reviewer's evaluation of that application or proposal as determined by the government official managing the review..."

${ }^{68}$ Charles Piller, Hidden Conflicts? 361 SCIENCE 17 (2018).

${ }^{69} \mathrm{Id}$. at 18 . It is notable that payments made to these physicians prior to a drug's approval were largely disclosed in journal publications, but not to the FDA. Id. at 17 . 


\section{CONFLICT OF INTEREST POLICIES, PROCEDURES AND CHALLENGES - AN INSTITUTIONAL PERSPECTIVE}

Although, as discussed above, many governmental funding agencies require research institutions to comply with their COI policies, these basic policies only set minimum thresholds and provide few practical guidelines for addressing conflicts of interest related to research. ${ }^{70}$ Institutions are responsible for interpreting these policies, devising strategies to identify and mitigate conflicts of interest, monitoring compliance and enforcing remedial or punitive measures in case of policy violations. Additionally, an institution may adopt its own COI policy for research not expressly covered by funding agency policies (e.g., internally funded research, research funded by private industry or philanthropic organizations, and research funded by state or federal agencies without COI policies). Some philanthropic orgnaizations such as the Pew Charitable Trusts have issued "best practice" recommendations for COI policies. ${ }^{71}$ And other institutional charters, codes of conduct and public commitments may also impact COI policies. ${ }^{72}$ Accordingly, COI policies and processes vary widely from institution to institution. ${ }^{73}$

Not all financial conflicts of interest are the same in kind or degree, and while the effects of conflicts of interest on collective researcher behavior suggest industry relationships (sponsorship, direct remuneration, equity, etc.) tend to result in favorable research outcomes for industry, the reasons why are not as well characterized. ${ }^{74}$ This

70 [PHS policy provides definitions (45 CFR Part 50, Subpart F, § 50.604) and guidance on managing conflicts (45 CFR Part 50, Subpart F, § 50.605); however, institutions are ultimately responsible for determining directness, relatedness, and significance of financial interests compared to the research when evaluating real or perceived financial conflicts of interest. In other words, determining the size and scale of the COI is the responsibility of the institution as are best methods to mitigate the COI when possible. Additionally, institutions may decide between identification of potential COIs is better accomplished by a COI Committee versus dedicated COI staff.]

71 Pew Charitable Trusts, Conflict-of-Interest Policies for Academic Medical Centers Recommendations for Best Practices (Dec. 2013), https://www.pewtrusts.org//media/legacy/uploadedfiles/phg/content_level_pages/reports/coibestpracticesreportpdf.pdf

72 For example, the 2007 document In the Public Interest: Nine Points to Consider in Licensing University Technology, which has been adopted by more than 100 universities and research institutions around the world, expressly commits its signatories to disclose conflicts of interest in the context of university technology transfer transactions. In the Public Interest: Nine Points to Consider in Licensing University Technology, Association OF University TeChnology MANAgERs (AUTM) (Mar. 6, 2007) http:/www.autm.net/AUTMMain/media/Advocacy/Documents/

Points_to_Consider.pdf (Point 4: "Universitites should anticipate and help to manage technology transfer related conflicts of interest").

${ }^{73}$ See Washburn, supra note 6, at 100.

74 Justin E. Bekelman, Yan Li, Cary Gross. Scope and Impact of Financial Conflicts of Interest in Biomedical Research. JAMA, January 22/29, 2003 - Vol 289, No. 4. Bekelman et al. conducted a metaanalysis showing industry relationships in general yielded more pro-industry research outcomes. Considering human subjects protections (HIPPA), potential experiments assessing decision-making behavior of conflicted individual researchers and their research outcomes are unlikely to ever get IRB or FDA approval. However, circumstantial evidence from a study evaluating prescribing patterns in physicians suggests that the amount of money does have a measurable effect on behavior (the more money a physician received from industry, the more likely the physician prescribed the company's drug) - Charles Ornstein, Mike Tigas, Ryann Grochowski Jones. Now There's Proof: Docs Who Get Company Cash Tend to Prescribe More Brand-Name 
complexity and uncertainty presents to institutions the daunting challenge of crafting robust policies and procedures to address a problem of indeterminate size and scale. In this section, we identify some challenges that institutions face when defining conflicts of interest, how best to identify and manage real or perceived conflicts of interest, and practical implications for conflicted researchers (and their research). This chapter uses the University of Utah's COI policy and its related procedures as an exemplar of the types of policies that large research universities may implement, but the authors recognize that these may not be the most effective or comprehensive methods for addressing conflict of interest issues related to research. Accordingly, they highlight potential benefits of other strategies.

\section{a. Institutional COI oversight and guidance}

Prior to 2002, at the University of Utah, each department handled its own conflicts of interest. The departments relied upon faculty to individually self-disclose any conflicts of interest connected to their research. In 2002, the University established a centralized COI office ("COI Office") with an associated committee ("COI Committee") to review and manage COIs from all academic units, but the COI Office still relied heavily upon investigator self-reporting of financial interests on a study-by-study-basis. In 2012, in response to the 2011 amendments to the PHS policy described above, the University amended its own COI policy to the present version, which outlines the duties and responsibilities of both the COI Office and the COI Committee that both serve to better identify and manage conflicts.

The COI Office reports to the Associate Vice President for Research Integrity, who reports to the Vice President for Research, who, in turn, reports to the President of the University. The COI Office currently employs a Director/Officer, a manager, an analyst and a part-time administrative assistant.

The main responsibilities of the COI Office include identification of potential individual and institutional conflicts of interest related to research, identification of potential conflicts of interest related to business transactions and oversight of employee compliance with the University's COI policy and management plans. The analyst reviews individual research projects and the investigators listed on them, identifies potential conflicts of interest, conducts annual compliance reviews of individuals with managed conflicts of interest and reports on the same. The manager assists with research analysis for institutional COIs, gathers information concerning financial interests and research protocols which may be relevant, assists with non-compliance investigations, reviews business transaction conflicts of interest, aids with information technology infrastructure to improve efficiency and system design, provides customer service to constituents, and engages in education outreach to the University. The Officer engages in all of the tasks of the manager and the analyst. In addition, the Officer addresses necessary policy changes within the COI Office and across other offices that require financial disclosures (for example, Industry Relations Office, Human Resources and the like). The Officer

Meds. ProPublicA, March 17, 2016. [https:/www.propublica.org/article/doctors-who-take-company-cashtend-to-prescribe-more-brand-name-drugs]. 
coordinates with department, academic units and other offices to assist in drafting internal COI policies, designs information technology processes to eliminate redundancy in the system and to automate the process for non-traditional areas of management, including investigations, non-compliance and remediation, builds checklists and management plans, administers the committee, and reports to the NIH and other funding agencies when necessary. The Officer also liaisons with the Office of General Counsel on sensitive matters where the COI policy and its operation have legal significance.

The COI Committee determines whether conflicts arise from significant financial interests and does so based upon the recommendation of the COI Office. The Committee also designs management plans best suited to eliminate or reduce bias in research created by the conflict. The Committee conducts investigations of non-compliance and recommends corrective action and sanctions when necessary and appropriate. Committee members also represent the COI Office in their respective departments and serve as ambassadors for the policy and its goals.

In 2018-2019, the Committee comprised twenty-one members drawn from faculty and staff across academic units, with required representation from critical units, including the School of Medicine and Health Sciences. ${ }^{75}$ Each member serves a staggered three-year term. A faculty member who has previously served on the Committee is selected as chair and serves a two-year term. The chair leads meetings, weighs in on policy disputes or interpretation issues, and votes with the Committee only when there is a tie.

The Committee meets once every three weeks to discuss agenda items set by the COI Office. Such agenda items include reviewing compliance with management plans, reviewing significant financial conflicts of interest, resolving conflict of interest disputes, and conducting institutional COI reviews pertaining to senior administrators. Each conflict of interest review is assigned to a seven to eight-person panel.

If the COI Office receives a complaint, which could include third parties raising issues about conflicts, out of compliance management plans, and other policy violations, the Officer investigates the basis of the complaint, consults with the committee, and determines whether to bring a full-blown investigation. When an investigation is warranted, the Officer sends the complaint and the COI Office's preliminary findings to the person complained of, who then has an opportunity to respond to the complaint. The Officer assigns an investigation to two Committee members who conduct the investigation, predominantly using interviews with all involved parties. The COI Office does background research by obtaining relevant publications, reviewing relevant consent documents, working with the Institutional Review Board ("IRB") when necessary to collect more information, and interviewing personnel who may have further information. The Committee members investigating a complaint have 90 days to present their findings to the Committee, which votes on whether or not a policy violation occurred and whether any recommended corrective actions are necessary. A letter report will be sent to the cognizant Senior Vice President and any relevant offices and supervisors connected to the investigators.

${ }^{75}$ For the complete details of committee membership, see https://regulations.utah.edu/general/rules/R1006A.php (last visited Sept. 7, 2018). 


\section{b. Significant financial interests}

As noted above, in 2011, the PHS implemented a conflict of interest policy governing PHS-funded institutions that shifted the responsibility of identifying conflicts of interest from investigators to the institutions that employ them. ${ }^{76}$ In the PHS policy, now reflected in many federal and institutional policies, including that of the University of Utah, the agency defines a financial conflict of interest as "a significant financial interest that could directly and significantly affect the design, conduct, or reporting of . . research."’77 Without further guidance, it falls to the institution receiving funding from PHS departments for projects covered by this policy to identify when significant financial interests create conflicts of interest by evaluating how a significant financial interest could "directly and significantly" affect an investigator's research.

This may appear straightforward at first glance, but an institution typically makes this assessment utilizing an extensive review process. The University of Utah requires all faculty and research personnel to report outside financial income and relationships that "reasonably appear related to his/her professional responsibilities to the University" through a centralized reporting mechanism. ${ }^{78}$ The University of Utah's Office for Sponsored Research ("OSP") and its IRB also maintain records of research personnel associated with sponsored projects and human subjects research. When a new award is administered through OSP, a milestone report generated by OSP, or a new application, continuing review, or amendment is submitted to the IRB, the list of investigators on the research project are checked in an automated financial disclosure system for up-to-date financial disclosures that may include a significant financial interest. Information associated with investigators who disclose a financial interest considered significant is forwarded to the university's COI Office, which conducts a manual review of each investigator's financial interest and the potential for the financial interest to impact the investigator's role in the design, conduct, or reporting of his research project.

To set standards and thresholds in this evaluation process, an institution may make assumptions and compromises to further the intent of its own COI policy. In some cases, the mission of the institution may be at odds with this intent. For example, a retention, promotion and tenure policy may require faculty to secure research funding to obtain tenure or promotion, or an invention policy might incentivize faculty to commercialize discoveries resulting from their research. In both cases, the incentives for faculty to engage in seeking external funding and commercialization of inventions could be undermined by a robust conflicts of interest policy tied to significant financial interests.

The University of Utah policy recognizes three categories of significant financial interests: 1) direct remuneration received from a business entity in the form of consulting,

${ }^{76}$ See 76 Fed. Reg. 53256, 53288 (Aug. 25, 2011); 45 C.F.R. Part 90 (2017).

7745 C.F.R. Part 93 (2017).

${ }^{78}$ University of Utah Policy 1-006, Individual Financial Conflict of Interest Policy (rev. 2012), available at https://regulations.utah.edu/general/1-006.php (last visited June 2, 2018). 
speaking, honoraria, employment and the like and/or an equity interest in a publicly traded company (where equity includes stock, stock options, or an ownership interest tied to fair market value) in an aggregate of $\$ 5,000$ or more in the previous 12 months ("direct remuneration interest"); 2) any remuneration received by an individual from a non-publicly traded entity in the previous 12 months that exceeds $\$ 5,000$ or when the individual holds any equity interest in a non-publicly traded entity ("non-public entity remuneration interest"); and 3) a filed patent, an asserted copyright, or income related to such patent or copyright rights and interests, including royalty income from the institution or others ("IP interest"). This policy explicitly excludes salary, travel reimbursements or other normal remuneration from the university if the investigator is employed by or appointed to the university, income from seminars, lectures, or teaching engagements sponsored by federal state or local government agency, institution of higher education, an academic teaching hospital, a medical center, or a research institute that is affiliated with an institution of higher education, income from service on advisory committees or review panels, or income from investment vehicles such as mutual funds or retirement accounts as long as the investigator does not control the funds in these vehicles. ${ }^{79}$

To apply this policy, the University of Utah's COI Office relies on investigator selfdisclosures of all financial interests reasonably related to her University responsibilities through a centralized business relationship reporting system where the questions are targeted to these specific categories. Moreover, as mentioned above, the system obtains information from OSP and IRB to link individual financial interests with research projects. The COI Office then obtains those financial disclosures from individual employees that fall into one or more of these three significant financial interest categories when the employees are listed as investigators on research project(s) in the OSP and IRB systems. Accordingly, the COI Office obtains information on all disclosed direct remuneration, equity interests and IP interests when those interests are disclosed by an individual associated with sponsored or human subjects research. ${ }^{80}$

The following are examples of circumstances that would likely be identified as significant financial interests:

1) A clinical faculty member is paid more than $\$ 5000$ by a pharmaceutical company to give a presentation about the benefits of one of its new drugs.

2) A post-doctoral fellow purchases over $\$ 5000$ of stock in a publicly traded company.

3) A laboratory manager purchases any amount of stock in a non-public company.

4) An investigator works with the institution's technology transfer office ("TTO") to file a patent application, where the investigator has assigned his interest in the invention to the institution but is entitled to a royalty in accordance with the institution's IP policy.

${ }^{79}$ University of Utah Policy 1-006, Individual Financial Conflict of Interest Policy (rev. 2012), § II.K.13), https://regulations.utah.edu/general/1-006.php. (last visited Sept. 11, 2018).

80 The ability to review only those files for which OSP or IRB have active research projects is a matter of historical infrastructure and a way to manage the number of disclosures reporting to the COI Office, which employs only two full-time reviewers. 

Office.

Importantly, the categorization process allows for almost no discretion by the COI

Once the COI Office obtains a disclosure flagged with a significant financial interest, the office staff reviews the disclosure for new information related to an existing project already processed for conflicts and for new projects with additional investigators associated with them. The office staff also ensures that all investigators have up-to-date attestations of financial interest in the university system.

\section{c. Evaluation of significant financial interests for conflicts}

After flagging a significant financial interest, the COI Office makes a preliminary assessment whether a potential financial conflict of interest exists for that individual investigator, and, if so, works with the COI Committee to manage, reduce, or eliminate the conflict using a management plan. Because the University of Utah policy does not define financial conflict of interest, the COI Office's working policy is to use the PHS definition: "a significant financial interest that could directly and significantly affect the design, conduct or reporting of research." $" 81$

The conflict of interest review process relies on peer assessment in reviewing these standards by the standing COI Committee. Once the COI Office identifies a potential financial conflict of interest for an investigator-that the significant financial interest relates to the investigator's research - it assigns the review to a committee meeting. If the review involves human subjects research or constitutes a new significant financial interest that has not yet been reviewed, the COI Office assigns the review to a committee member for further review. If the committee reviews a new project with a conflict that has already been reviewed for related previous non-human subjects projects, it applies the same management plan as before and sends it to the meeting without assignment to an individual committee member but the Committee will modify the existing plan if necessary based on differences in study design and personnel.

After completing his own review of assigned reviews, each committee member presents to the full committee the case for or against a financial conflict of interest to the committee. The committee then deliberates and determines direct and significant relatedness between the investigator's significant financial interest and the research in question. The reviewer submits a recommended management plan and the committee votes to accept the recommendation as is or to amend the plan. Management strategies are discussed more fully below.

8142 C.F.R. Part 50.603. The 2011 amendments to the NIH COI policy (see Section II.A, supra) resulted in a paradigm shift in identifying conflicts of interest in research. Prior to the 2011 amendments, the University of Utah required researchers to self-identify and report conflicts of interest related to specific studies. The change to NIH policy required researchers to disclose to the institution all of their financial interests "reasonably related" to their institutional responsibilities. Identification of conflicts of interest became the responsibility of the institution through study-by-study review of investigators' financial interests relative to the aims of the research. 


\section{d. Management of financial conflicts of interest}

Many financial conflicts of interest can be managed, reduced, or eliminated entirely. The committee uses multiple strategies that focus on transparency, data integrity, protections for students and subordinates, IP reporting and recusal from commercialization activities, and enhanced human subjects research scrutiny.

If, upon preliminary review, the COI Office identifies a potential conflict, its staff reaches out to the investigator and begins gathering information about the business relationship or other significant financial interest, IP and other information that could be relevant to the committee's review, including whether students or subordinates are participating in the research or whether the research may generate new IP. The investigator is also asked about data integrity — can the data be blinded, can a non-conflicted investigator collect the data and the like. The information collected intends to reduce the bias on the research by allowing for a customized management plan for every case that best reduces, eliminates, or manages the conflict of interest.

The most common strategy for addressing conflicts of interest is transparency. Conflicts should be disclosed in publications and presentations given by the investigator. This is consistent with the requirements of many academic journals that also require authors to self-disclose conflicts of interest. ${ }^{82}$ The rationale for disclosing in this manner is so that a consumer of the research will be made aware that the results could be susceptible to potential bias and is better equipped to interpret the research outcomes. Other types of transparency include disclosing conflicts to the research team, disclosing to subordinates and students who may be working for the conflicted investigator (and prohibiting evaluation or review of those subordinates and students by the conflicted investigators and prohibiting conflicted investigators from delaying publication of work by the students and subordinates that is related to the financial interest), and in the case of human subjects research, disclosing the conflict of interest to potential research participants. Here, the rationale is to educate those individuals working with the conflicted investigator to ensure that potential bias from the financial interest is recognized. Disclosure in consent documents allows human subjects to assess the cost and benefits of being involved in a research study with a conflicted investigator. Another form of disclosure required by PHS is to publicly disclose or have a means to distribute information about PHS-funded studies in which a conflict of interest has been identified. The University of Utah publishes such studies on a publicly available website. ${ }^{83}$ It has also independently decided to disclose any financial conflicts of interest involving human subjects research on that website as well.

A second area of concern suggesting management is data integrity. The COI Committee will use one or more of several strategies including blinding the data, prohibiting conflicted individuals from data collection and analysis, requiring a nonconflicted peer to review the study and file reports with the COI Committee, having a nonconflicted individual to review data and results prior to submission for publication, or in

\footnotetext{
${ }^{82}$ See Section VI, infra.

83 [https://coi.utah.edu/_documents/coi_list_0415.pdf]
} 
more extreme cases having a non-conflicted peer monitor the research and submit annual reports to the COI Committee. The Committee may also notify a data and safety monitoring board, if one exists.

When the Committee identifies a financial conflict of interest in a human subjects research study, the investigator receives greater scrutiny. The University of Utah COI policies include a rebuttable presumption that the conflicted investigator cannot participate in the research at all. The Committee reviewer contacts the conflicted investigator making him aware of the rebuttable presumption, and invites the investigator to present evidence of credible, compelling circumstances to rebut the presumption and allow the investigator allowed to continue to work on the study. ${ }^{84}$ In addition to disclosing conflicts to the potential participants, the Committee might prohibit the conflicted investigator from obtaining patient consent to participate in the study and invite a non-conflicted member of the research team to consent thereby removing any type of coercion by the conflicted investigator in convincing the subject to participate in the research. Relatedly, if the PHS funds a study where an investigator receives a management plan of any variety, the COI Office must report the plan to the agency.

Every manageable conflict that the committee identifies is given a mitigation plan with four basic disclosure-related components. First, the committee will conduct an annual compliance review for each conflicted investigator to ensure that person complies with the management plan assigned by the committee. Second, the committee requires that the investigator disclose the financial conflict of interest in any and all publications related to the project. Third, the investigator must disclose the financial conflict of interest in all professional presentations related to the project. Fourth, the investigator must disclose his conflict of interest to the entire research team. Additionally, the committee asks whether the conflicted investigator is working with students or subordinates on the project, and if so, the investigator must disclose his conflict to them as well. If the research project has human subject participants, the investigator must disclose his conflict of interests in the consent documents.

When an inventor of IP is investigating his own IP in a non-human subjects sponsored research project, the investigator receives a standard management plan with additional disclosures to the technology transfer office if the project will generate new IP owned by the institution. The investigator will be prohibited from negotiations regarding the IP. If the data cannot be blinded, a non-conflicted investigator must collect and analyze the data. If this isn't possible, the committee may assign a peer monitor to oversee the entire research project and to report annually to the committee. When the conflicted investigator is not a principle investigator ("PI"), the PI can oversee the project with respect to conflicts. If the PI is conflicted, the committee might choose a monitor not on the study or someone who is not a subordinate to the conflicted investigator.

${ }^{84}$ See Protecting Patients, Preserving Integrity, Advancing Health: Accelerating the Implementation of COI Policies in Human Subjects Research vi-vii, xii, 6-7, 15 (AAMC-AAU Advisory Committee on Financial Conflicts of Interest in Human Subjects Research (2008), https://members.aamc.org/eweb/upload/protecting\%20Patients, $\% 20$ Preserving\%20Integrity.pdf pages (last visited Sept. 11, 2018). 


\section{e. Non-research conflicts of interest}

In addition to the measures described above to eliminate the effect of conflicts of interest on research, state law and university policy prohibit an individual from participating in any decision-making with respect to a transaction when he or she has a direct financial interest in the transaction. ${ }^{85}$ The COI committee provides an additional check on these non-research conflicts of interest that may arise through a variety of business transactions by institutional employees. This includes subawards and subcontracts that derive from grants and contracts, license agreements related to IP, and general institutional procurement (for example, using research funding to buy lab supplies or other inventory or services from a company owned by the researcher).

When an institutional employee submits a disclosure to the business relationship reporting system that includes a significant financial interest in a business entity, the system requires the employee to accept a boilerplate notice that participating in business transactions on behalf of the university when the financial interest is on the other side that the person must recuse himself and not participate in any decision-making processes with the transaction. ${ }^{86}$ Because the university offices involved in procurement, sponsored projects, and technology transfer engage in business transactions that may involve employees with conflicts, those offices have been instructed to communicate with the COI Office the names of those employees who have received the boilerplate notice. When one of the employees identified has a financial interest relevant to the transaction, the COI Office confirms to the inquiring office that the individual has accepted the terms of the mandatory notice. If the conflicted employee must provide input to the transaction-for example, if the conflicted employee would provide important information to the negotiation of a contract - then the employee must recuse himself from the process, provide in writing to all individuals involved that a conflict exists, and, in most cases, have a non-conflicted supervisor ensure that negotiations are at an arms' length. If an employee

85 Utah State Public Officials and Employees Ethics Act [https://le.utah.gov/xcode/Title67/Chapter16/67-16.html?v=C67-16_1800010118000101]

86 The University of Utah uses the following standard language of management regarding business transactions: "I have disclosed a significant financial interest in the entity(ies) named above, which currently transact, or may in the future transact, business with the University of Utah. I will advise my immediate supervisor of the existence of this financial interest. In the event that the University transacts business with this entity, I will not participate in any aspect of that process (e.g., negotiating license agreements, research proposals, subcontracts, and procurement contracts, including the preparation of specifications, evaluations or bids, committee deliberations/voting) on behalf of the University. To the extent that my University responsibilities would normally result in my participation in such transactions, I will assure that any minutes associated with that transactional process reflect my recusal from the decision-making process. If my University responsibilities require me to provide input into the selection of products or services from or to this business entity, at the time of providing such input, I will clearly disclose in writing to the University decision-makers the existence of my financial interest in the business entity. I am aware that the Utah Public Officers and Employees Ethics Act, Utah Code Ann. $\S \S 67-16-1$ to -15 (the Ethics Act) creates additional legal obligations for me, including obligations related to my participation in a private business that enters business transactions with my public employer, and I acknowledge that I remain personally responsible for complying with the Ethics Act.] 
does engage in one of the prohibited things after making his agreement, the employee is out of compliance with this agreement and the COI Committee will conduct a review and offer recommendations.

\section{f. Monitoring and non-compliance}

After a conflicted investigator receives a management plan from the COI committee, the committee continues to oversee the investigator's compliance with the plan. The committee also oversees compliance with the general employee disclosure policy that enables identification of significant financial interests and the institution's polices with regard to non-research related business transactions.

Questions of compliance may be brought to the COI Office or the Committee by anyone concerned, anonymously or not. The COI Office may learn about disclosure failures and underreporting of financial interests from relevant institutional actors, including internal audit offices and the like. The COI Office also may discover noncompliance on its own, including by use of the CMS Open Payments Search Tool, which tracks payments from pharmaceutical and medical device companies to physicians and teaching hospitals. ${ }^{87}$

If the COI Office suspects non-compliance by an employee with reporting requirements, by an investigator subject to a management plan, or by an employee engaging in prohibited business transactions, the COI Office opens an investigation into the alleged non-compliance, and assigns the investigation to two committee members. The committee members, in consultation with COI Office, conduct the investigation and report their findings to the committee. The committee then votes on recommended actions within its purview (such as recusal from the research study) and sanctions, if appropriate. Sanctions will be recommended to the cognizant university administrator for enforcement and follow up. If the study has been funded by the PHS, the COI Office must report findings of non-compliance to the agency. ${ }^{88}$

\section{g. Institutional conflicts of interest}

As discussed in Section II above, certain interests held by an institution and its senior leadership could compromise or appear to comprise the integrity of research conducted at the institution. Therefore, the University of Utah developed an institutional COI ("ICOI") policy that is designed to manage, reduce, or eliminate such institutional financial conflicts of interest related to human subjects research in the same manner as the

${ }^{87}$ CMS Open Payments - https://openpaymentsdata.cms.gov/ - was created in accordance with section 6002 (also known as the Physician Payments Sunshine Act) of the Affordable Care Act of 2010, which required manufacturers of drugs, medical devices, and biologics to report payments to recipients. See 42 U.S.C. $\S 1320 \mathrm{a}-7 \mathrm{~h}$ et seq.

8842 C.F.R. $\S \S 50.604,50.605$ (2018) (describing the institution's reporting obligations with respect to financial conflicts of interest). 
individual COI policy discussed above. As a result, the institutional COI policy is very similar in form and function to the individual COI policy. For senior personnel (who may not be directly involved with research but do act in a supervisory role to the investigators conducting the research), the definition of SFI is the same as in the individual policy. In the ICOI policy, the university financial conflicts of interest are defined as: 1) University ownership of equity in a company (stock, stock options, of at last $5 \%$ of the company), 2) University-owned technology that is currently licensed or has previously been licensed, including royalties received for such licensing agreements, and 3) significant gifts from a company to a university. Significant gifts means gifts to the university of securities, other property, or cash exceeding $\$ 100,000$ over the previous four academic years.

The COI Office cross-references financial disclosures by senior personnel and human subjects research projects to identify institutional conflicts. When a senior personnel-related institutional financial interest has been identified in a human subjects research study, the review goes through committee review in the same manner as an individual financial conflict of interest. The committee advises an ICOI Officer on management of the conflict.

To identify university financial interests related to human subjects research, the COI Office cross-references the university's development office database along and the technology transfer office's database of university owned IP, university company ownership and university licensing agreements with research study information from the IRB to identify potential financial interests. If one has been identified, the ICOI office evaluates the financial interest to determine whether a conflict exists, using the same standard for evaluation as the committee uses for individuals and senior personnel. If an ICOI can be managed, the ICOI officer unilaterally enters a management plan for university conflicts of interest and the management strategies are generally more comprehensive because data integrity and patient safety then require non-university oversight.

\section{ACADEMIC JOURNAL POLICIES}

As described above, many institutional COI policies require that investigators disclose known conflicts of interest relating to a research study in any published article reporting the results of that study. As explained by Gottlieb and Bressler, "Disclosure of a $\mathrm{COI}$ in a publication invites readers to consider whether the study design was objective, data were appropriately analyzed, and interpretations and conclusions accurately reflect the data." 89

There are several standardized processes for disclosing such conflicts today, the best known of which is the COI disclosure template made available by the International Committee of Medical Journal Editors ("ICMJE"). ${ }^{90}$ The ICMJE template requests that

89 Julie D. Gottlieb \& Neil M. Bressler, How Should Journals Handle the Conflict of Interest of Their Editors? 317 J. AM. MED. AsSN. 1757, 1757 (2017).

${ }^{90}$ Int'l Comm. Med. J. Eds, Conflict of Interest Disclosure Forms, http://www.icmje.org/abouticmje/faqs/conflict-of-interest-disclosure-forms/. See Joseph T. Thornton, Conflict of Interest and Legal 
authors of works for publication disclose far more than most federal or institutional policies. Disclosed financial interests, for example, include all "financial relationships with entities in the bio-medical arena that could be perceived to influence, or that give the appearance of potentially influencing, what you wrote in the submitted work." ${ }^{91}$ It goes on to clarify that "if your article is about testing an epidermal growth factor receptor ("EGFR") antagonist in lung cancer, you should report all associations with entities pursuing diagnostic or therapeutic strategies in cancer in general, not just in the area of EGFR or lung cancer." ${ }^{22}$ Moreover, the ICMJE template seeks disclosure of all sources of revenue paid to the author or his/her institution on his/her behalf during the prior 36 months, not only the sponsor of the particular study that is the subject of the article. ${ }^{93}$

While the transparency afforded by such disclosures is often sufficient to give reviewers and readers the information they need to assess potential bias of an author's work, some journals impose requirements beyond simple disclosure to certain types of work. For example, some journals prefer not to publish opinion pieces (editorials, commentaries and review articles) in which an author has a conflict of interest, as a truly objective opinion may be desired in these pieces. ${ }^{94}$

In addition to authors, the editors, reviewers and publishers of scientific journals may also have conflicts of interest with respect to the subject matter of the articles appearing in them. The editors of most scientific journals are non-staff volunteers who are recognized authorities in a field. As such, these individuals may have conflicts of interest that affect their impartiality when it comes to selecting and editing articles. The same applies to peer reviewers who are invited to review and make recommendations regarding articles submitted to a particular journal. Conflicts in these cases include not only financial ties, but any significant personal, employment or co-authorship relationship or any significant scientific or ideological difference of opinion. ${ }^{95}$ In the case of editors and peer reviewers, a conflicted individual is generally required to recuse himself or herself from reviewing the article with which a conflict exists. ${ }^{96}$ And most importantly, editors and peer reviewers are expressly forbidden from using knowledge of the work they are reviewing for their own personal gain (financial or academic) before it is published. ${ }^{97}$

Issues for Investigators and Authors, 317 J. AM. MED. ASSN. 1761, 1761 (2017) ("The ICMJE form is the industry standard that many journals require").

${ }^{91}$ Int'l Comm. Med. J. Eds, ICMJE Form for Disclosure of Potential Conflicts of Interest, Instr. 3.

92 Id.

${ }^{93} I d$.

94 See Am. Med. Assn., AMA Manual of Style: A Guide For Authors And Editors, Ch. 5.5.1 (10 th ed. 2009), Phil Fontarose \& Howard Bauchner, Conflict of Interest and Medical Journals, 317 J. AM. MED. ASSN. 1768, 1770 (2017).

95 See Sara Rockewell, Ethics of Peer Review: A Guide for Manuscript Reviewers 5-9, https://ori.hhs.gov/sites/default/files/prethics.pdf ; Fontanarosa \& Bauchner, supra note 94, at 1771.

96 See Int'1 Comm. Med. J. Eds, Recommendations for the Conduct, Reporting, Editing, and Publication of Scholarly Work in Medical Journals 4 (Dec. 2017), http://www.icmje.org/about-icmje/faqs/icmjerecommendations/

${ }^{97} I d$. 
Journal publishers, too, may encounter conflicts of interest, particularly if they enter into financial arrangements with private firms for special issues, advertising spreads and other features. ${ }^{98}$ Ensuring that such arrangements do not compromise the editorial selection and quality of a journal's content is critical, and few journals have robust procedures in place to do so. ${ }^{99}$

Despite the disclosure mechanisms in place at scientific journals, these processes are not perfect. In some cases, authors or others may fail, inadvertently or intentionally, to disclose a relevant COI. One recent study reported that 100 researchers who received median compensation of approximately $\$ 100,000$ from surgical and medical device manufacturers reported a relevant COI in only $37 \%$ of publications. ${ }^{100}$ Another recent study found that one third of oncologists publishing the results of clinical trials failed to make full disclosure of the payments that they received from trial sponsors. ${ }^{101}$

Such failures to disclose COIs are frequently detected by journal readers. Often a reader will notice that a particular author who previously disclosed a COI in a different article or journal has failed to disclose the same COI in a more recent publication. In addition, as Thornton observes, "bloggers and other 'COI watchers' scour the literature for failures to disclose." 102 Most journals provide a mechanism for readers to report suspected failures to disclose COIs and will investigate questionable cases. ${ }^{103}$ In the case of Dr. Baselga of Memorial Sloan Kettering, the failure to disclose was uncovered by investigative journalists from the New York Times and ProPublica. ${ }^{104}$

If a failure to disclose a COI is discovered, a journal may require the author to issue an acknowledgement, letter of explanation, apology and/or correction. ${ }^{105}$ Journal editors caution, however, that allegations regarding a failure to disclose "need not be judged through the prism of "the unreasonable, uninformed, or overly zealous." 106 These words of caution may belie the fact that, despite formal policies, few journals take punitive measures against authors who fail to make required disclosures. ${ }^{107}$

${ }^{98}$ See Thomas J. Easley, Medical Journals, Publishers, and Conflict of Interest, 317 J. AM. MED. Assn. 1759,1760 (2017).

${ }^{99} \mathrm{Id}$.

${ }^{100}$ Kasra Ziai, et al., Association of Compensation from the Surgical and Medical Device Industry to Physicians and Self-declared Conflict of Interest, JAMA SuRGERY, Aug. 15, 2018.

${ }^{101}$ Cole Wayant, et al., Financial Conflicts of Interest Among Oncologist Authors of Reports of Clinical Drug Trials, JAMA Oncology, Aug. 30, 2018.

102 Thornton, supra note 90, at 1762.

103 See id. at 1762; Fontanarosa \& Bauchner, supra note 94, at 1770.

104 Ornstein \& Thomas, supra note 3.

105 See Thornton, supra note 90, at 1762; Fontanarosa \& Bauchner, supra note 94, at 1770.

106 Thornton, supra note 90, at 1762.

107 See Ornstein \& Thomas, supra note 3 (reporting that the American Assn. for Cancer Research stated that it "had never barred an author from publishing" despite failures to comply with disclosure rules). 


\section{CONCERNS, CRITIQUES AND FURTHER RESEARCH}

In response to the increasing support of academic research by the private sector and a few highly-publicized instances of academic misfeasance, federal funding agencies, research institutions and scientific journals have developed a complex system for identifying, assessing, reporting and mitigating conflicts of interest. Most agree that these procedures are necessary to ensure the integrity of the research enterprise and to preserve public trust.

This being said, some consider the current system for reporting and managing conflicts of interest to be unduly burdensome: an over-reaction to a few egregious cases of research misconduct. ${ }^{108}$ Research institutions estimate that they spend large sums complying with federal and institutional COI rules. One survey by the AAMC estimated that 71 institutions spent $\$ 23$ million to comply with the revised PHS rules in the year after they were implemented. ${ }^{109}$

Many have criticized the lack of standardization among COI reporting metrics and requirements, creating unnecessary work and administrative overhead for researchers and providing inconsistent and difficult-to-understand information to the public. ${ }^{110}$ One 2015 study published in Nature observed that "institutions have vastly different standards for what constitutes a conflict - and [] they classify relatively few relationships between researchers and industry as troublesome."111

Others have argued that COI disclosures create a barrier to effective industryacademia partnerships and collaborations, both increasing the time required to form collaborations and reducing the ability and desire of both academics and industry partners to enter into collaborations. ${ }^{112}$ Critics also argue that COI reporting requirements results in decreased educational opportunities for researchers, given reductions in corporate funding, events and paid speeches by industry experts. ${ }^{113}$

Concerns over failure to comply with $\mathrm{COI}$ reporting requirements could lead to over-disclosure by researchers who zealously report every possible financial and other interest in an abundance of caution. Such over-reporting could lead to an exaggerated view of the prevalence of conflicts, as well as obscuring important conflicts among the mass of trivial ones. ${ }^{114}$

Yet others believe that under-reporting of conflicts is still a problem, particularly as institutions make the initial determination whether a particular COI is likely to lead to

${ }^{108}$ IOM 2014, supra note 18, at 11.

${ }^{109}$ Reardon, supra note 38, at 300-01.

110 IOM 2009, supra note 17, at 8-10.

111 Reardon, supra note 38, at 300.

112 IOM 2014, supra note 18, at 9.

${ }^{113} I d$.

114 See Allen S. Lichter, Conflict of Interest and the Integrity of the Medical Profession, 317 J. AM. MED. ASSN. 1725 (2017). 
bias. ${ }^{115}$ Likewise, the transparency-based rationale that underlies most federal and institutional COI policies has been criticized as too weak, particularly in the case of human subjects research. Several groups, including the Association of American Medical Colleges ("AAMC"), the Association of American Universities ("AAU") and the Institute of Medicine ("IOM"), have recommended that researchers be excluded from human subjects research if they have a financial interest in the outcome of the research. ${ }^{116}$ Jeffrey Botkin, Associate Vice President for Research at the University of Utah, has recently called for more stringent penalties for researchers who violate journal or institutional COI rules. ${ }^{117}$ Responding primarily to the Baselga incident at Memorial Sloane Kettering, Dr. Botkin recommends that failures to disclose COI be considered forms of research misconduct -conduct that can lead to serious penalties that "strike[] at the basic integrity of anyone who pursues a scientific career." 118

These concerns and critiques point to the need for more research in the area of COI. Among the issues that could benefit from further research are the causal relationship between financial COI and research bias, the cost of implementing and maintaining COI reporting and management systems, the impact of COI disclosures on research subjects, and the best means for integrating disclosure mechanisms across the research enterprise. ${ }^{119}$ It is hoped that a greater, evidence-based understanding of COI and their effects on research may pave the way for continuing improvements in the COI system. iceberg").

${ }^{115}$ Reardon, supra note 38, at 300 (according to one researcher, "we're just seeing the tip of the

116 IOM 2009, supra note 17, at 9 and Recommendation 4.1.

117 Jeffrey R. Botkin, Viewpoint: Should Failure to Disclose Significant Financial Conflicts of Interest be Considered Research Misconduct? 320 J. Am. Med. Assn. 2307 (2018). Dr. Botkin does not speak on behalf of the University of Utah in this article.

118 Id. at 2308.

${ }^{119}$ See, e.g., William W. Stead, The Complex and Multifaceted Aspects of Conflicts of Interest, 317 J. Am. Med. Assn. 1765, 1767 (2017). 